\title{
DESIGN AND DEVELOPMENT OF A MOBILE SENSOR BASED THE BLIND ASSISTANCE WAYFINDING SYSTEM
}

\author{
Barati, F. ${ }^{1}$ and M.R. Delavar ${ }^{2}$ \\ ${ }^{1}$ IT MSc. Student, Dept. of Information Technology Eng., College of Eng., \\ University of Qom, Qom, Iran \\ f.barati@stu.qom.ac.ir \\ ${ }^{2}$ Center of Excellence in Geomatic Eng. in Disaster Management, School of Surveying and Geospatial Eng., College of Eng., \\ University of Tehran, Tehran, Iran \\ mdelavar@ut.ac.ir
}

KEYWORDS: The Blind, Wayfinding, Mobile sensor, ultrasonic sensor, Geospatial Information System, GPS

\begin{abstract}
:
The blind and visually impaired people are facing a number of challenges in their daily life. One of the major challenges is finding their way both indoor and outdoor. For this reason, routing and navigation independently, especially in urban areas are important for the blind. Most of the blind undertake route finding and navigation with the help of a guide. In addition, other tools such as a cane, guide dog or electronic aids are used by the blind. However, in some cases these aids are not efficient enough in a wayfinding around obstacles and dangerous areas for the blind. As a result, the need to develop effective methods as decision support using a non-visual media is leading to improve quality of life for the blind through their increased mobility and independence. In this study, we designed and implemented an outdoor mobile sensor-based wayfinding system for the blind. The objectives of this study are to guide the blind for the obstacle recognition and the design and implementation of a wayfinding and navigation mobile sensor system for them.
\end{abstract}

In this study an ultrasonic sensor is used to detect obstacles and GPS is employed for positioning and navigation in the wayfinding. This type of ultrasonic sensor measures the interval between sending waves and receiving the echo signals with respect to the speed of sound in the environment to estimate the distance to the obstacles. In this study the coordinates and characteristics of all the obstacles in the study area are already stored in a GIS database. All of these obstacles were labeled on the map. The ultrasonic sensor designed and constructed in this study has the ability to detect the obstacles in a distance of $2 \mathrm{~cm}$ to $400 \mathrm{~cm}$. The implementation and the results obtained from the interview of a number of blind persons who employed the sensor verified that the designed mobile sensor system for wayfinding was very satisfactory.

\section{INTRUDUCTION}

People with visual disabilities must make an extra effort to insert themselves into society and to a participate as citizens in the world around them [1]. The blind due to the lack of vision especially in unfamiliar and large scale environments faced with enormous problems in their wayfinding [2,3]. The access of the blind and visual impaired to the world are limited. They often rely the sense of hearing, touch and smell in order to collect information about the world $[4,5]$. The blind able to glimmer from the surroundings with their senses. According to World Health Organization reports, about 45 million blind and 180 million visually impaired people live worldwide. It should be noted that $80 \%$ of the blind live in developing countries. For this reason scientific research for the blind seems necessary to help them in their routing and navigation. To assist the blind in their navigation, the power of geospatial information system (GIS) as a science and technology of the integration and analysis of spatially referenced information, multimedia presentation as well as the use of maps and geospatial information $[6,7]$ and a system for portable navigation with a global positioning system (GPS) are used. 
A number of systems to guide the blind for wayfinding around the world are designed and developed $[8,9,10]$. MOBIC system is a prototype of a navigation system for the blind which consists of a Pre-journey System (MOPS) to assist users in planning journeys and the MOBIC Outdoor System (MOODS) to execute these plans by providing the users with orientation and navigation assistance during the journeys [11]. Drishti is a wireless navigation system for pedestrians which combines different technologies including wearable computers, detection and analysis of voice, wireless network, geospatial information system (GIS) and global positioning system (GPS) [12]. Noppa project is a personal navigation system that uses an information server as an interpreter between the user and internet information systems [13]. CASBLIP project added images and maps of the surrounding environment to support navigation of people with visual impairment $[14,15]$. SMART VISION project uses GPS for outdoor and WIFI for indoor navigation system with various modules such as GIS and database localization with radiofrequency identification (RFID) tags on the sidewalk [16, 17]. ARGUS project based on the global navigation satellite system and data coming from open street map and city network provides a virtual guidance rope for the blind and partially sighted persons or people working in environments with low visibility [18]. Some of these systems uses audio interface which may make some difficult in navigation for the blind in the crowded and noisy environments. For this reason huge amount of the information provided by these aids systems is leading to confusion for the blind. The designed system in this paper, in addition to use vibration to resolve the ambiguity, needs less training compared with other aid systems for the blind. This system which has a low cost ables to provide the online information about the obstacles to the blind.

The proposed system has an ultrasonic sensor for obstacle detection as a navigation aid which is designed and developed in this research. The outline of the remaining parts of the paper is as follows: Section 2 describes research methodology and case study. Section 3 describes system design and simulation. Section 4 describes the evaluation of the designed system and finally conclusion is presented in section 5 .

\section{METHODOLOGY}

The proposed system as a navigation and wayfinding support includes GPS, a map and an ultrasonic sensor to detect the obstacles.

The methodology of the research has been shown in Figure 1. According to Figure 1, the obstacles in the study area have been identified and information about the obstacles such as their titles and coordinates imported into the GIS database. The study area is a part of Tehran, the capital of Iran. The blind person begins to move from the Hasantash Street in Dowlat Avenue in the north of Tehran as his/her origin with an ultrasonic sensor at hand to Iran the Blind Society as his/her destination. While a blind person is moving towards the obstacles, the sensor vibration is activated. The blind person according to the vibration severity of the sensor, changes his/her walking direction. There are some obstacles in the implemented phase such as trees, stream and poles between the origin and the destination. The study area specified with Longitude in a range of $51^{\circ} 27^{\prime} 14.28^{\prime \prime}$ to $51^{\circ} 27^{\prime} 09.34^{\prime \prime}$ and Latitude in a range of $35^{\circ} 46^{\prime} 41.59^{\prime \prime}$ to $35^{\circ} 46^{\prime} 41.18^{\prime \prime}$ presented in Figure 2. The blind person with an ultrasonic sensor and GPS detects the obstacles on his/her way and due to the sensor vibration whose vibration severity is related to the distance to the obstacle, continues to move in a collision free path. In the proposed system the process shown in Figure 3 is performed. Static data obtained from the map and dynamic data obtained from the sensor and GPS as an input are loaded to the programming module. In the programming module the static data registered in GIS database integrated with dynamic data to be able to assist detecting the obstacles and finally vibration is undertake as an output alert to the blind. Geospatial information system is used in the implemented system in order to calculate distance to the obstacles which integrates the map and ultrasonic sensor data and if the blind distance to the obstacle is less than a given threshold, the sensor vibration will be activated.

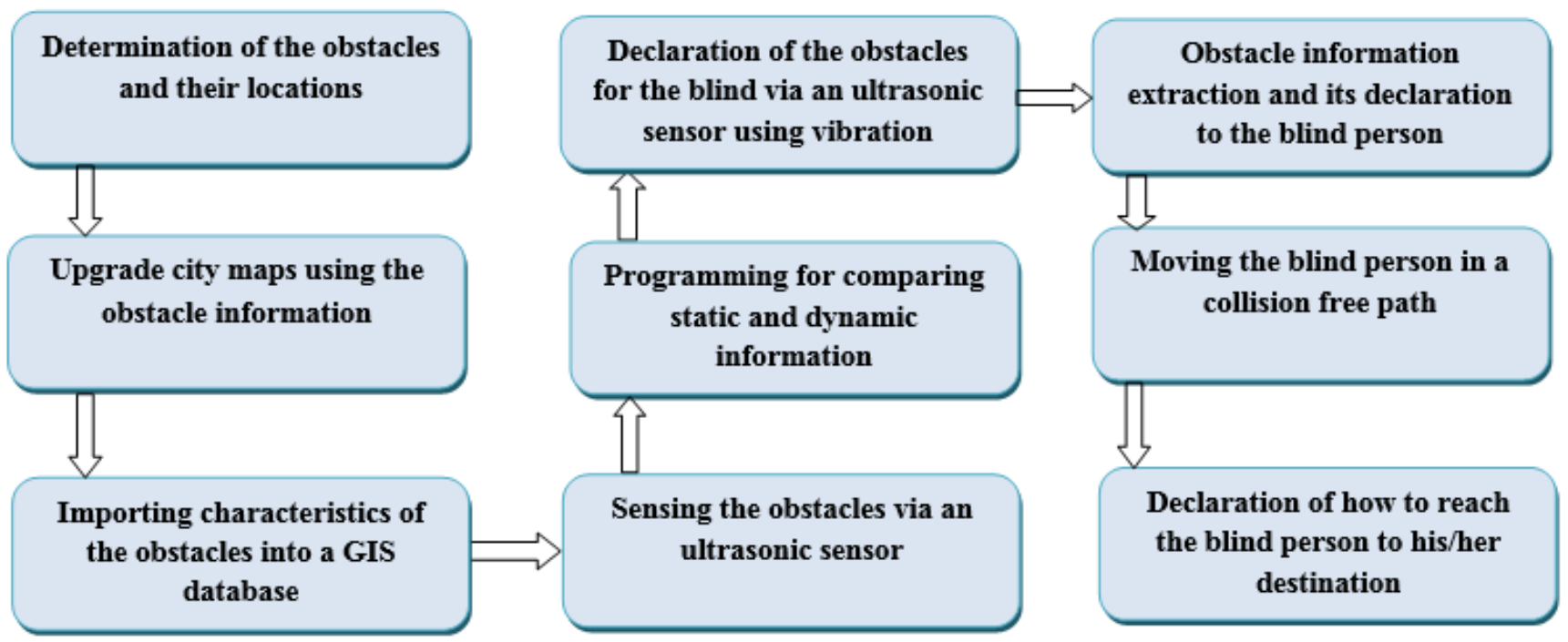

Figure 1. Research methodology 


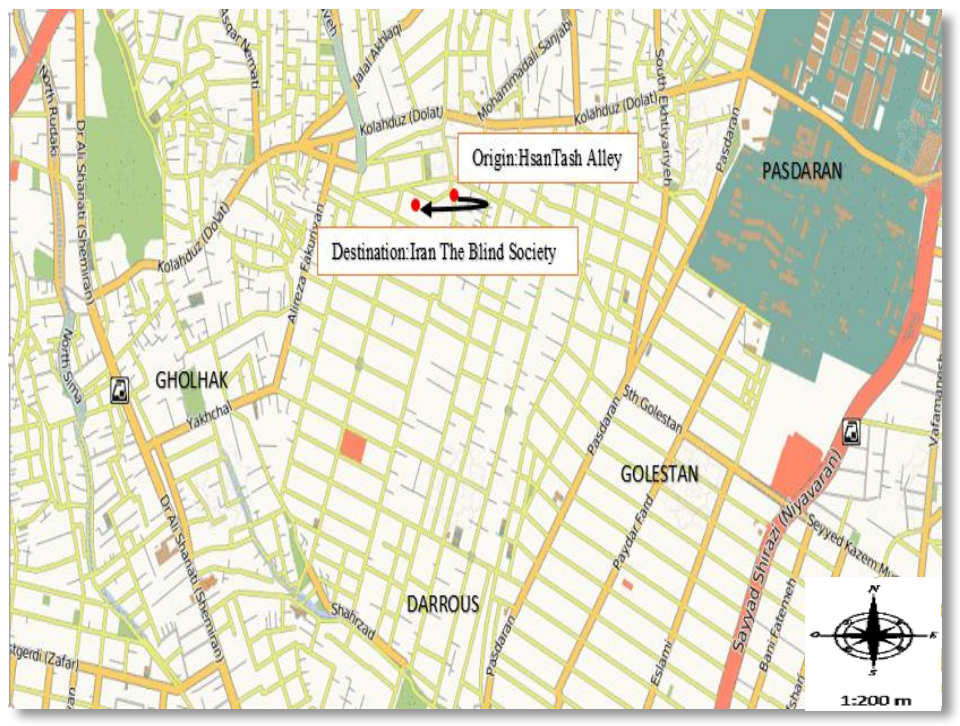

Figure 2. The area study

\section{SYSTEM DESCRIPTION AND SIMULATION}

\subsection{System Description}

The system is used in an outdoor space. In this study the ultrasonic sensor is used to detect the obstacles [19, 20, 21, 22] and GPS is employed for positioning and navigation in the wayfinding process. This type of ultrasonic sensor measures the interval between sending waves and receiving the echo signals with respect to the speed of sound in the environment to estimate the distance to the obstacles. In this paper we used the HC-SR04 module that includes ultrasonic transmitters, receiver and control circuit. This module contains 4 pins (Voltage converter controller (Vcc), Trigger, Echo and Ground).

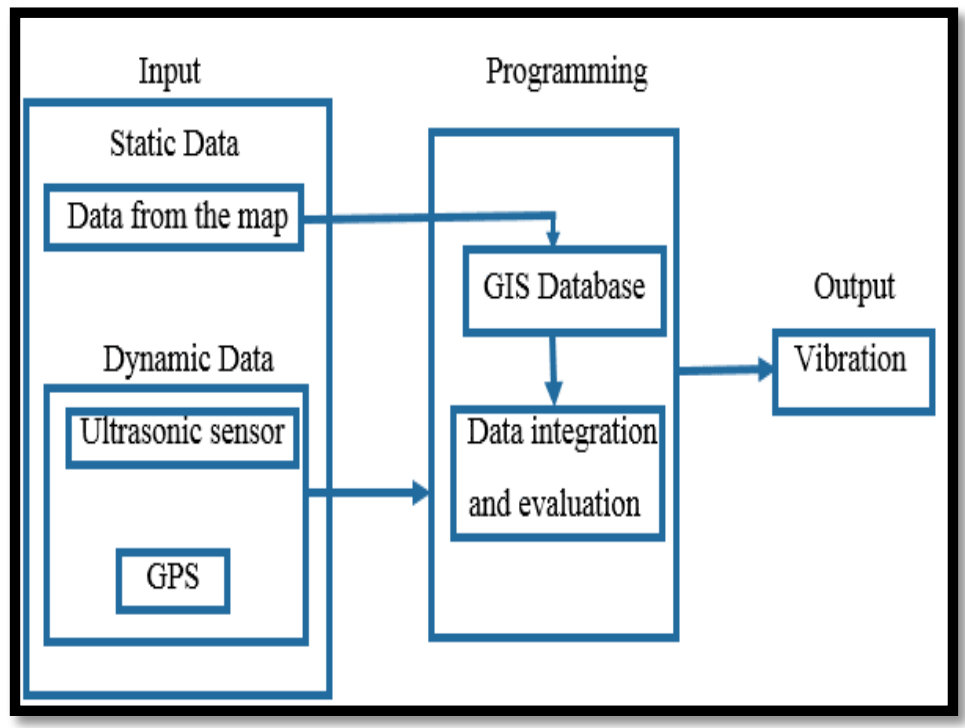

Figure 3. The process performed

The Vcc pin is the power supply and trigger pin is the activation pin for the module. To launch this module the pulse to the trigger pin is applied, then wait until the pin echo be activated activate (or to be one) after it, the timer is activated then wait for the echo pin to be deactivated (or to be zero). When the echo pin is zero, the timer stopped which is equal to time interval between sending trigger signal and receiving echo signal.

To calculate the distance to the obstacles, this time is divided to two parts and considering $\mathrm{X}=\mathrm{VT}$, the distance to the obstacles is calculated:

$\mathrm{X}$ : Distance to the obstacles

V: Sound propagation speed (340 meter/Sec.)

T: Time

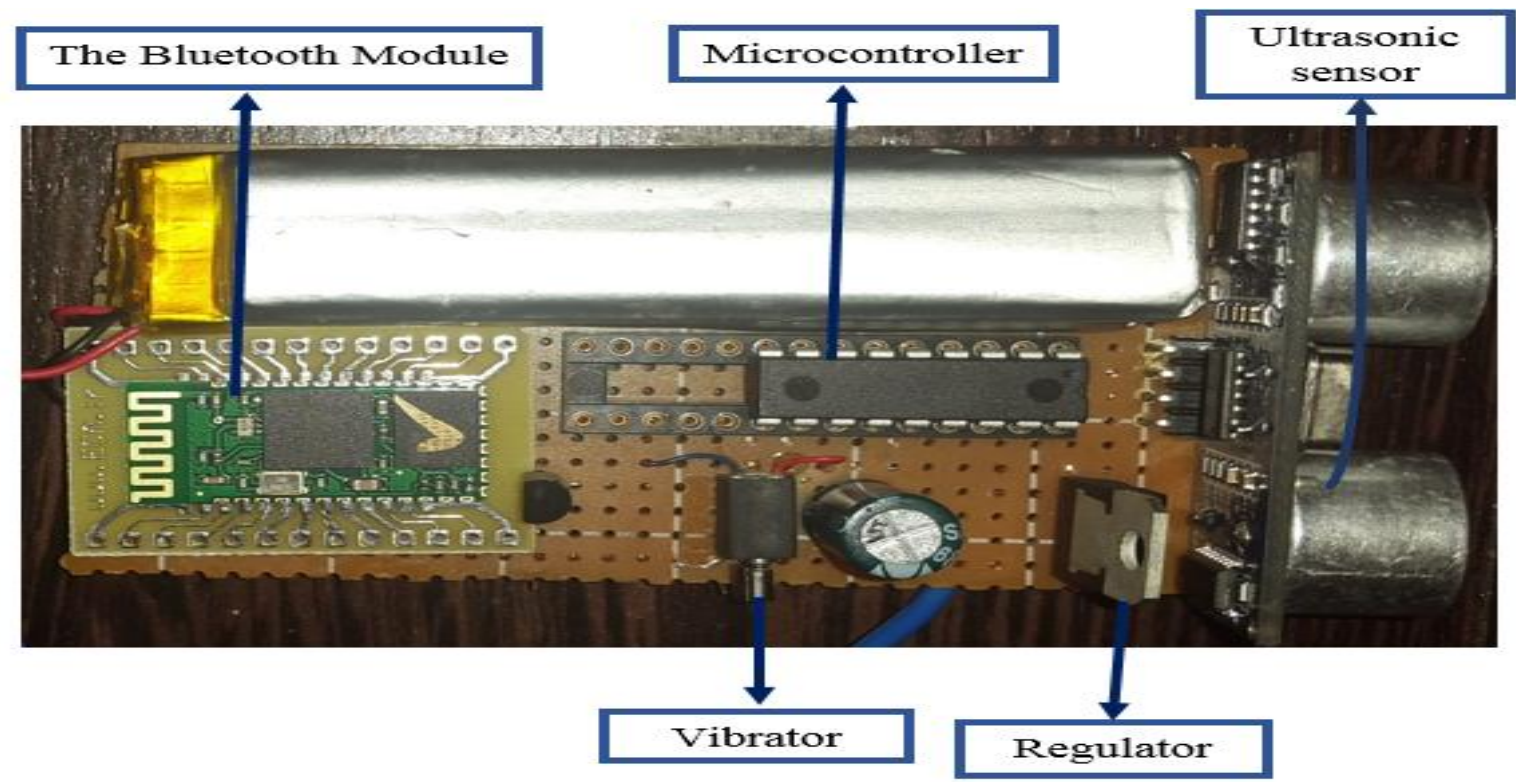

Figure 4. Ultrasonic sensor developed 
The Bluetooth module used in order to send data from the sensor to the computer system. A view of the ultrasonic sensor designed and developed in this research shown in Figure 4. The coordinates and characteristics of all the obstacles in the study area are already stored in the GIS database. All of these obstacles were labeled on the map. The ultrasonic sensor has the ability to detect the obstacles in a distance of $2 \mathrm{~cm}$ to 400 $\mathrm{cm}$. Each system designed for the blind generally contains three main parts as follow [23, 24, 25]:

- A module for recognizing the location

- A computer system that contains a GIS with the information to assist the users to undertake wayfinding

- $\quad$ The user interface

As shown in Figure 4 on side ultrasonic sensor is a vibration motor whose sound is related to the distance from the obstacle change vibration intensity. When the blind getting closer to the obstacles, the vibration intensity is increased.

\subsection{Simulation}

In addition to the design and test of the implemented system, a simulation has been performed: To simulate the implemented

\section{EVALUATION}

In order to evaluate the designed system, an interview was arranged with the blind. Each participant in the interview could offer additional information and suggestions about the designed system. At first, a brief introduction about the designed system is presented to the blind. Participants in the interview become familiar with the sensor and its performance. After the blind introduction to the sensor, an outdoor test was implemented. The system is tested on 15 blinds in Iran The Blind Society and for this purpose a questionnaire was designed.

The questions asked the blind to answer the following issues:

- The time to detect the obstacles

- The ease of system use

- The errors in obstacles detection

The survey consists of 9 females and 6 males whose age range 21 to 61.The purpose of this survey is to evaluate the blind satisfaction level with respect to the designed and implemented system. The results from the interview are presented in Table 1.

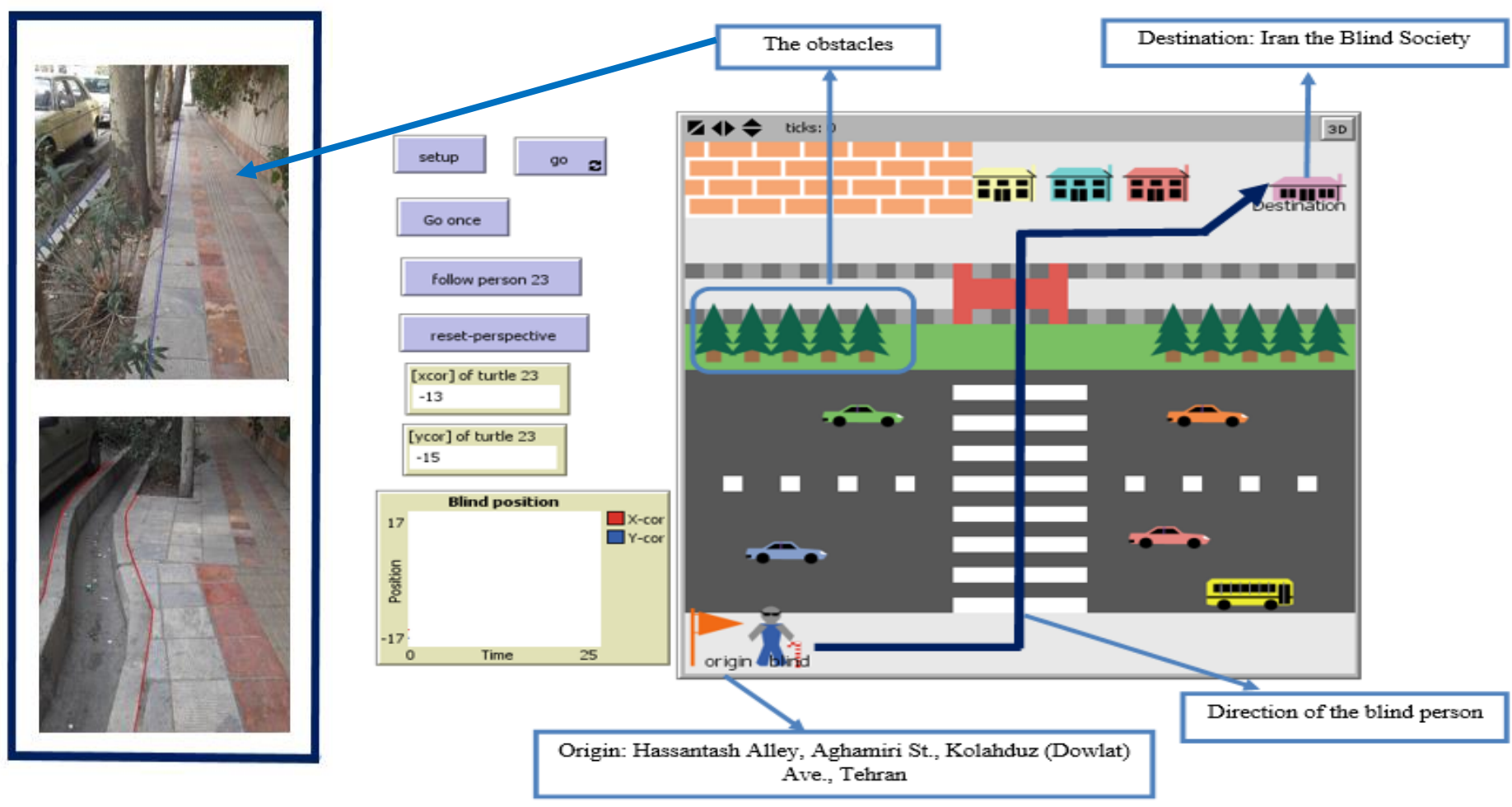

Figure 5. Simulation of the designed system

system, Netlogo software Version 5.1.0 was used as shown in Figure 5. In this simulation, the blind person from the origin to the destination moves in an obstacle free path. Also the obstacles such as trees and cars in this simulation are presented. The blind and obstacles are considered as agents.
A quality parameter was calculated as follows:

Satisfaction level of navigation system for the blind $=$ number of detected obstacles number of obstacles 
Number of detected obstacles $=51$

Number of obstacles $=60$

\begin{tabular}{|c|c|c|c|c|}
\hline & $\begin{array}{c}\text { The consent } \\
\text { from the user } \\
\text { interface } \\
\mathbf{( \% )}\end{array}$ & $\begin{array}{c}\text { The } \\
\text { portability } \\
\mathbf{( \% )}\end{array}$ & $\begin{array}{c}\text { Ease of } \\
\text { use } \\
\mathbf{( \% )}\end{array}$ & $\begin{array}{c}\text { Time to } \\
\text { detect the } \\
\text { obstacles } \\
\mathbf{( \% )}\end{array}$ \\
\hline $\begin{array}{c}\text { Female } \\
\text { opinion }\end{array}$ & 75 & 80 & 70 & 60 \\
\hline Male opinion & 83 & 85 & 88 & 73 \\
\hline $\begin{array}{c}\text { The total } \\
\text { participants }\end{array}$ & 78 & 81 & 76 & 67 \\
\hline
\end{tabular}

Table 1. The results of the evaluation

According to the test, $85 \%$ of the blind claimed the quality and the ease of use of the system. These blind people took five minutes to reach to the destination using a cane without the implemented system. However, it took three minutes for them to reach to the destination using the designed system.

\section{CONCLUSION}

The system implemented in this study consists of a map-based and vibrator motor along with the ultrasonic sensor to help the blind move in the safe and collision free path. The cost of implementing this system compared to that of other systems in the navigation aid is very low. The designed system also has a light weight. This system using a mobile sensor assists the blind to navigate from the origin to the destination. In addition, the implemented system reduced the time for the navigation. According to the evaluation results in a collision free path, the mobile navigation system has achieved the blind satisfaction. The designed system is able to integrate data from maps with data from the sensor and according to the specified position via GPS it guides the blind more accurately. The developed system has a limitation to recognize the type of the obstacles and their involved risks. Solving these limitations is the next step of this research.

\section{REFERENCES}

[1] Sanchez, J., Saenz, M.,2010. Metro navigation for the blind. Computers \& Education,55(3), 970-981.

[2] Bradley, N.A., Dunlop, M.D., 2005, An experimental investigation into wayfinding directions for visually impaired people. Personal and Ubiquitous Computing, 9(6), 395403.
[3] Rodriguez-Sanchez, M.C., Moreno-Alvarez, M.A., Martin, E., Borromeo, S., Hernandez-Tamames, J.A., 2014. Accessible smartphones for blind users: a case study for a wayfinding system. Expert Systems with Applications, 41(16), 7210-7222.

[4] Rajput, D., Ahmed, F., Ahmed, H., Shamshad, A., 2014. Smart obstacle detector for blind person. Biomedical Engineering and Medical Imaging, 1(3), 31-40.

[5] Nandhini, N., Vinoth chakkaravarthy, G., Deepa, P., 2014. Talking assistance about location finding both indoor and outdoor for blind people, Innovative Research in Science, Engineering and Technology, 3(2), 9644-9651.

[6] Hong, j., Suh, E., Kim, S., 2009. Context-aware systems: A literature review and classification, Expert Systems with Applications, 36(4), 8509-8522.

[7] Gajevic, L., 2014, Context information in development of Geographic Information Services for inclusion of persons with disabilities. International Workshop on Context-Awareness in Geographic Information Services (CAGIS), Austria, pp. 6271.

[8] Petrie, H., V., Johnson, T., Strothotte, A., Raab, S., Fritz and R., Michel, 1996. MOBIC: Designing a travel aid for blind and elderly people. Navigation, 49(1), 45-52.

[9] Ran, L. ,Helal, S. , Moore, S. , 2004. Drishti: an integrated indoor/outdoor blind navigation and system and service. Pervasive Computing and Communications, 36, 23-30.

[10] Alshbatat, A.I., 2013. Automated mobility and orientation system for blind or partially sighted people. Smart Sensing and Intelligent Systems, 6(2), 568-582.

[11] Sundaresan, Y., Gupta, S., Sabeel, W., 2014. Smart wearable prototype for visually impaired. Engineering and Applied Sciences, 9(6), 929-934.

[12] Fernandes, H., Conceicao, N., Paredes, H., Pereira, A., Barroso, J., 2012. Providing accessibility to blind people using GIS. Universal Access in the Information Society, 11(4), 399-407. 
[13] Ari, V., K., Sami, 2004. NOPPA Navigation and Guidance System for the Blind, VTT Industrial Systems, Finland.

[14] Dunai, L., L., Tortajadn, F., Simon, 2014. Obstacle detectors for visually impaired people. Proc. International Conference Optimizing of Electrical and Electronic Equipment, 22-24 May, Bran, pp. 809-816.

[15] Guillermo, P. ,Dunai, L. ,Praderas, CASBLIP a new cognitive object detection and orientation system for impaired people. Proc. COGSYS Conference, ETH Zurich, Jaunary, 27$28,2010$.

[16] Bhambare, R.R., A., Koul, S.M., Bilal, S., Panday, 2014. Smart vision system for blind. Engineering and Computer Science, 3(5), 5790-5795.

[17] Hans, J.M., Barroso, J., Fernandes, H., 2011.The smartvision navigation prototype for blind users. Digital Content Technology and its Applications, 5(5), 351-361.

[18] Otaegui, O., Loyo, E., Carrasco, E., 2012. ARGUS: assisting personal guidance system for people with visual impairment. Proc. ISOCARP Congress. Russia

[19] Mustapha, B., Zayegh, A., Begg, R., 2013. Ultrasonic and infrared sensors performance in a wireless obstacle detection system. Proc. International Conference Artificial Intelligence, Modelling and Simulation, pp. 487-492.

[20] Rodriguez, A., Yebes, J., Alcantarilla, F., Bergasa, L., 2012. Assisting the visually impaired: obstacle detection and warning system by acoustic feedback. Sensors, 12(12), 1747617496.

[21] Mpitziopoulos, A., Konstantopoulos, C., Gavalas, D., Pantziou, G., 2011. A pervasive assistive environment for visually impaired people using wireless sensor network infrastructure. Network and Computer Applications, 34(1), 194-206.

[22] Prattico, F., Cera, C., Petroni, F., 2013. A new hybrid infrared-ultrasonic electronic travel aids for blind people. Sensors and Actuators A: Physical, 201, 363-370.

[23] Loomis, Golledge, Klatzky,, 1998. Navigation System for the Blind .Presence, 7(2), 193-203.
[24] Ljupko, S., Andelic, V., Pavlinusic, I., Blind people guidance system. Proc. Central European Conference Information and Intelligent Systems, Croatia, 19-21 september, 2012, pp. 427-431.

[25] Hossain, E., Khan, R., Ali, A., 2011. Design and data analysis for a belt-for-blind for visual impaired people. Advanced Mechatronic Systems 3, No. 5/6, 384-397. 